\title{
Sexual dysfunction and mode of delivery in Chinese primiparous women: a systematic review and meta-analysis
}

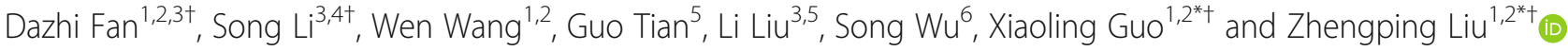

\begin{abstract}
Background: Up to now, there is controversy over the effect of delivery mode cesarean delivery and spontaneous vaginal delivery on sexual function. Therefore, we did a systematic review and meta-analysis in postpartum women to explore the mode of delivery, cesarean delivery, and spontaneous vaginal delivery and differences in postpartum sexual function (short- and long-term) in Chinese primiparous women.

Methods: Comprehensive electronic searches of PubMed, EMBASE, Web of Science, Elsevier Science Direct, Cochrane Library, the Chinese Biological Medical Literature database and the Chinese National Knowledge Infrastructure database were conducted to identify any study in each database published to August 31, 2017. The primary outcome was the sexual satisfaction and the secondary outcomes were resumed intercourse and sexual pain in the postpartum.

Results: We identified 10 studies with a total population of 2851 in the present meta-analysis. Five and six eligible articles were respectively included for sexual satisfaction in postpartum at 3- and 6 months. Compared with vaginal delivery group, two time points were all not found statistically significance $(\mathrm{OR} 1.53,95 \% \mathrm{Cl}$ 0.93-2.49; OR 1.15, 95\% Cl 0. 95-1.39, respectively) in cesarean and spontaneous vaginal delivery group; in resumed intercourse and sexual pain domains, they were all significantly, with an overall OR of $2.05(95 \% \mathrm{Cl} 1.36-3.11)$ at 3 months, $1.50(95 \% \mathrm{Cl} 1.04-2.16)$ at 6 months and $0.29(95 \% \mathrm{Cl} 0.24,0.36)$ at 3 months, $0.73(95 \% \mathrm{Cl} 0.58,0.93)$ at 6 months, respectively. With the passage of time, the gap was closing. Sensitivity analysis was indicated a good stability of the meta-analysis in each domain.

Conclusions: In conclusion, this meta-analysis indicated that the mode of delivery, cesarean and spontaneous vaginal delivery did not affect postpartum sexual satisfaction (short- and long-term) and appeared to have minimal effect on the long-term resumed intercourse and sexual pain in Chinese primiparous women. Primiparous women should be more cautious to choose cesarean section in order to preserve sexual function.
\end{abstract}

Keywords: Cesarean delivery, Vaginal delivery, Sexual function, Meta-analysis

\section{Background}

There has been concern about progressively increasing rates of caesarean section in many parts of the world, particularly among developing countries such as China $[1,2]$. The caesarean section rate was more than $40 \%$ in many Chinese hospitals, while in some cases, it was up to $80 \%$ [3], which was now higher than the upper limit of $15 \%$ recommended by the WHO's guidelines [4].

\footnotetext{
*Correspondence: fsguoxl@163.com; liuzphlk81@outlook.com ${ }^{\dagger}$ Equal contributors

${ }^{1}$ Foshan Institute of Fetal Medicine, Southern Medical University Affiliated Maternal \& Child Health Hospital of Foshan, Foshan, Guangdong 528000, China

Full list of author information is available at the end of the article
}

Long-term consequences associated with caesarean sections had been reported in many previous studies, including pelvic floor disorders, reduced fertility, placental abnormalities, mental distress, and female sexual dysfunction [5-7].

Female sexual function was considered a social issue, and pregnancy and delivery are considered contributory factors. Available data suggested that postpartum female sexual dysfunction was common in many countries [8-10]. The prevalence among postpartum women was as high as $41 \%$ to $83 \%$ in the first 3 months after delivery [8] and $18-30 \%$ of postpartum women still complained experiencing sexual problems at 6 months after delivery [9]. Among all domains 
of sexual problems, pain during intercourse, sexual dissatisfaction and delay in resuming intercourse were the most prevalent sexual problems for women and were negatively associated with the quality of life after childbirth [11-14]. In a study by Declercq and colleagues [12], almost half (48\%) of mothers accused experiencing a painful perineum over the first 2 months postpartum, and $2 \%$ reported the pain persisting for at least 6 months.

Currently, Chinese women may prefer birth by caesarean section to vaginal delivery because they think it was safer and free from pain and anxiety and also may increase postpartum sexual life quality [15]. Up to now, numerous reports had been engaged with the task of exploring female sexuality in postpartum in Chinese women [16-25]. However, there was controversy over the effect of delivery mode cesarean delivery and spontaneous vaginal delivery on sexual function. Several studies had revealed the association between sexual function and delivery mode $[18,22$, 23]. In contrary, other studies demonstrated no association between mode of delivery and sexual function [20, 21, 24].

Therefore, we did a systematic review and meta-analysis in postpartum women to explore the mode of delivery, cesarean delivery, and spontaneous vaginal delivery and differences in postpartum sexual function (short- and long-term) in Chinese primiparous women.

\section{Methods}

This meta-analysis was performed following the guidelines from the Preferred Reporting Items for Systematic reviews and Meta-Analysis (PRISMA) statement (Additional file 1: Table S1) [26].

\section{Literature search}

Identification and selection of relevant studies from PubMed, EMBASE, Web of Science, Elsevier Science Direct, Cochrane Library, the Chinese Biological Medical Literature database (CBM) and the Chinese National Knowledge Infrastructure database (CNKI) were searched for articles concerning the postpartum sexual function in Chinese primiparous women with planned/unplanned cesarean or spontaneous vaginal delivery mode. The last search update was on August 31, 2017. Keywords used to identify relevant articles were "mode of delivery", "cesarean delivery", "vaginal delivery", and "sexual", "sexual function" or "sexual dysfunction". We used MeSH terms including "Delivery, Obstetric" [Mesh], "Cesarean Section" [Mesh], and "Sexual Dysfunction, Physiological" [Mesh]. Relevant articles in the reference lists were identified to obtain additional published studies.

\section{Inclusion and exclusion criteria}

Studies meeting the following inclusion criteria were considered for this meta-analysis: (I) Clinical trials and prospective or retrospective studies investigating the correlation of the sexual function with the mode of delivery, planned/unplanned cesarean and spontaneous vaginal delivery, not instrumental delivery, among Chinese primiparous women; (II) Findings providing sufficient information for the estimation of odds ratios and 95\% confidence intervals; and (III) the publication was in English or Chinese. Only studies published in peer-reviewed journals were included, data from letters and meetings abstracts were not eligible. Studies were also rejected if they did not meet the inclusion criteria or if they reported duplicated or useless data.

\section{Data extraction}

Two authors (DF and SL) independently screened and determined the relevant studies and extracted the relevant data from each study and subsequently assessed the data to estimate reliability. The following information was obtained from the studies: first author, publication year, number of participants, age at time of delivery (mean, median, range), mode of delivery (planned/unplanned cesarean delivery, and spontaneous vaginal delivery), and sexual function outcomes (sexual satisfaction, resumed intercourse and sexual pain) in the first 3 and 6 months postpartum. The primary outcome of interest in this review was the sexual satisfaction in postpartum. And the secondary outcomes were resumed intercourse and sexual pain in postpartum. Any discrepancies were settled through discussion until a consensus was reached. Using Cohen's kappa statistic, the consistency coefficient was 0.94 in the data extraction.

\section{Risk of bias assessment}

Two authors (GT and LL) independently assessed the risk of bias of the selected studies using the Strengthening the Reporting of Observational Studies in Epidemiology (STROBE) Statement, which consisted of a checklist of 22 items [27]. Each item was classified as "no" (high risk), "yes" (low risk), or "unclear" to facilitate assessing the risk of potential bias in the title and abstract, introduction, methods, results, discussion, and other information sections of articles [27]. In order to report the results in percentages, the total number of "no", "yes", or "unclear" was added and divided by the total number of items for each study and multiplied by 100 [28]. A consensus reviewer (SW) resolved any observed discrepancies. The consistency coefficient was 0.96 in the risk of bias assessment.

\section{Statistical analysis}

The ORs and 95\% CIs were combined to obtain the effective value. A heterogeneity test based on $I^{2}$ and $\mathrm{Q}$ statistics was performed. The heterogeneity of individual ORs was calculated using Cochran chi-square $\left(x^{2}\right)$ tests and quantified with the $I^{2}$ statistic. $I^{2}$ less than 25\% denoted low heterogeneity, a value from 25 to $50 \%$ indicated moderate heterogeneity, and a value greater than $50 \%$ indicated substantial heterogeneity 
[29]. Significant heterogeneity was determined at a $p$ value less than 0.10 . The random effects model was used when heterogeneity was observed between primary studies. And the fixed effects model was used for analysis when no heterogeneity was observed. The impact was considered statistically significant when the 95\% CI did not overlap with 1 . Sensitivity analyses were performed to assess the stability of the results. Due to the small number of the included studies, publication bias cannot be assessed in this study. Statistical significance was considered for a $p$-value of less than 0.05 for summary OR. All calculations were performed using Review Manager Version 5.3 (provided by The Cochrane Collaboration, available from www.ccims.net/revman) and STATA version 11.0 (Stata Corporation, College Station, TX, USA).

\section{Results}

Literature search

A total of 189 citations were retrieved from electronic databases. A flowchart of the study selection was provided in Fig. 1. After removal of duplicates, 122 publications were independently assessed for eligibility. After preliminary screening of titles and abstracts utilizing the aforementioned criteria, 16 articles were identified for full-text review. Of these, 6 were further excluded for various reasons (including 1 review article, 2 relevant outcomes not reported, and 3 accurate data not reported), leaving 10 eligible articles (2851 participants) [16-25] and were included in the metaanalysis. The study-level risk of bias results shown in Fig. 2. All of the included studies did not discuss limitations of the studies while nine studies did not give the source of funding and the role of the funders for the studies. Eight of ten studies did not describe any efforts to address potential sources of bias, explain how the study size was arrived at, or report other analyses done. The demographic characteristics of the participants in each study were shown in Table 1.

\section{Sexual satisfaction}

As showed in Table 2, 5 studies (740 participants in cesarean delivery group, 742 participants in spontaneous vaginal delivery group) were included in the meta-analysis for sexual satisfaction at 3 months postpartum. Six

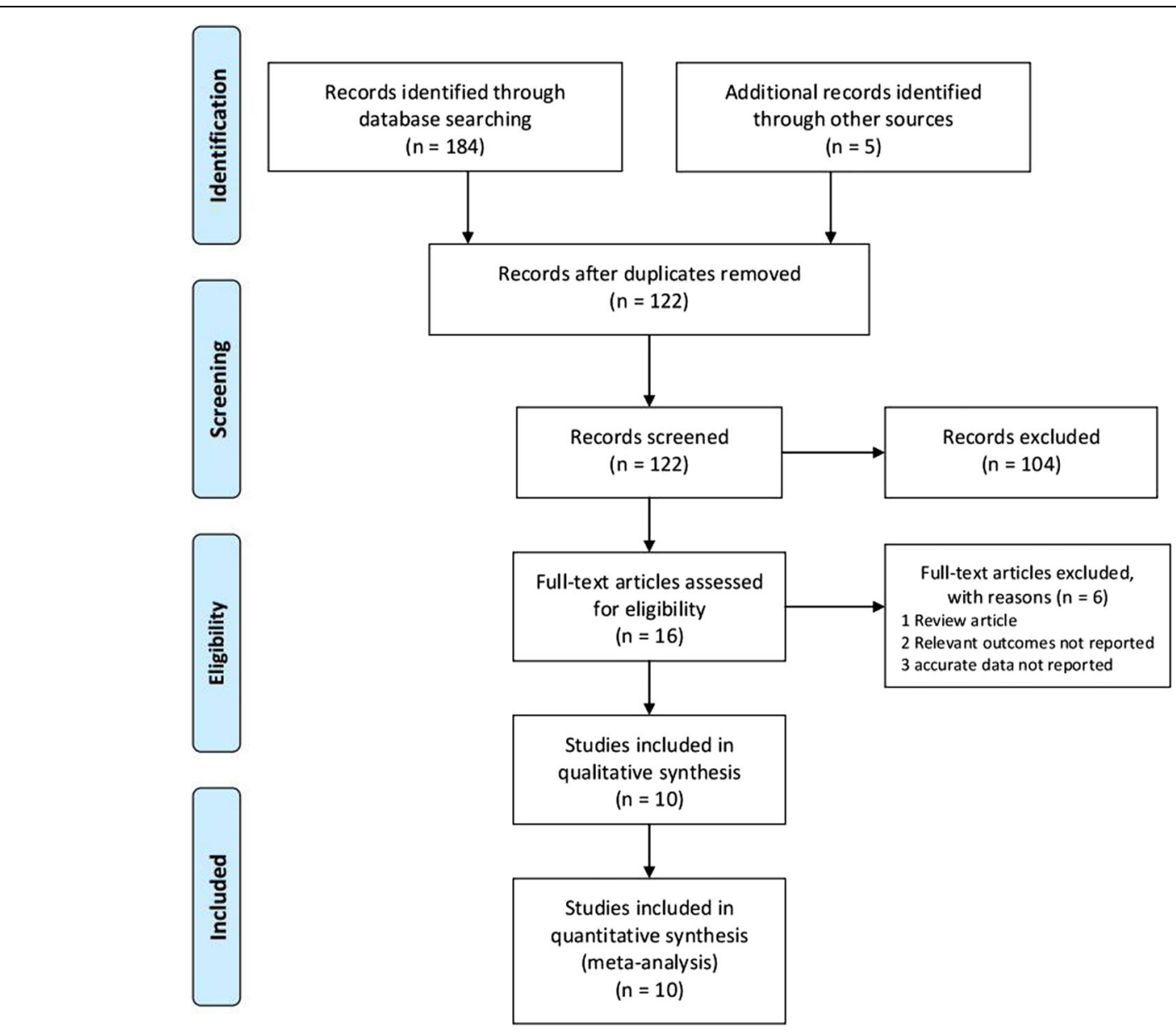

Fig. 1 PRISMA flowchart showing the study selection process 


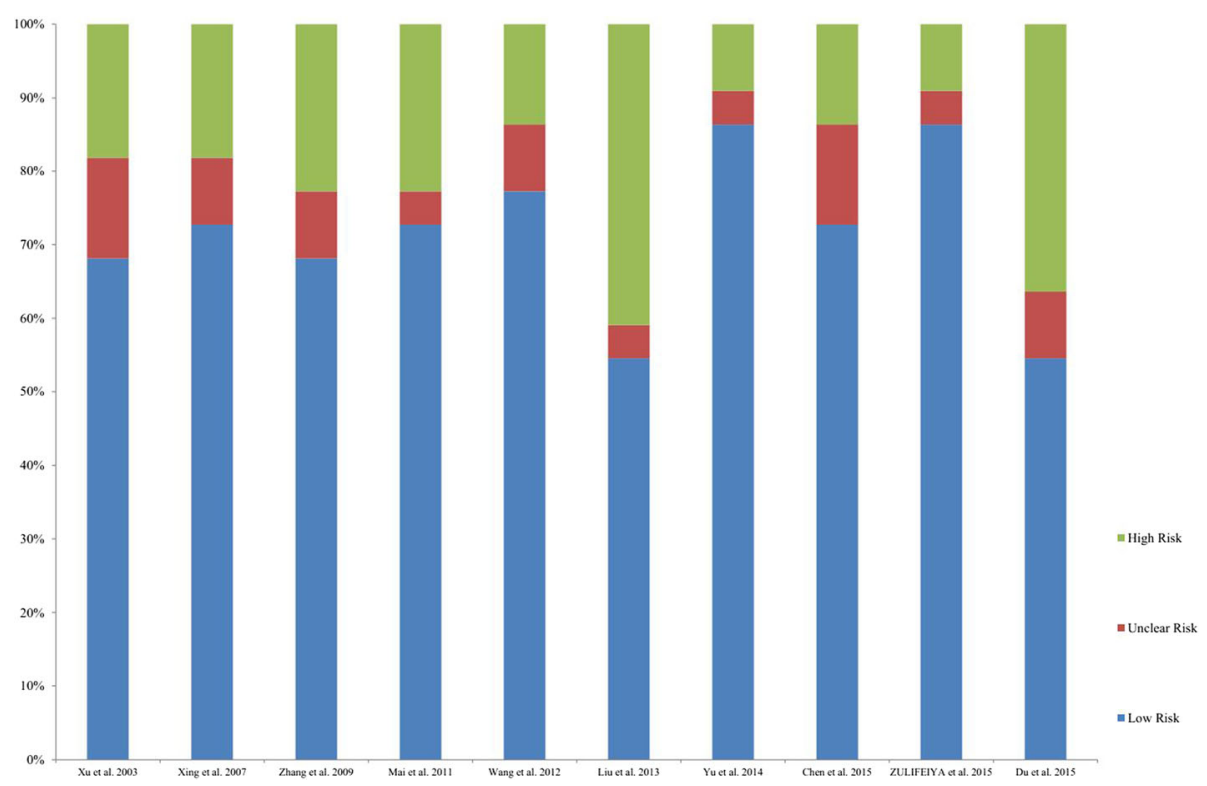

Fig. 2 Risk of bias assessment using STROBE statement for each study. The statement consisted of a checklist of 22 items. Each item was classified as "no" (high risk), "yes" (low risk), or "unclear" to facilitate assessing the risk of potential bias in the title and abstract, introduction, methods, results, discussion, and other information sections of articles. In order to report the results in percentages, the total number of "no", "yes", or "unclear" was added and divided by the total number of items for each study and multiplied by 100

studies, including 1011 participants in cesarean delivery group and 901 participants in spontaneous vaginal delivery group, were included at 6 months postpartum. Compared with vaginal delivery group, there were all not found statistically significance in sexual satisfaction between the two groups at the two time points (OR 1.53, 95\%CI 0.93-2.49; OR 1.15, 95\%CI 0.95-1.39, respectively) (Fig. 3).

Sensitivity analysis was performed to assess the stability of the meta-analysis. When any single study was deleted, the corresponding pooled ORs were changed slightly (Additional file 2: Table S2; Additional file 3: Figures S1-S2), with the statistically similar results indicating a satisfactory stability of the meta-analysis.

\section{Resumed intercourse and sexual pain}

Nine (2449 participants) and eight (2329 participants) studies were included for resumed intercourse in postpartum at 3 months and 6 months, respectively. Compared with vaginal delivery group, participants were all earlier resumed intercourse in cesarean delivery group at 3 months and 6 months postpartum, with an overall OR of 2.05 (95\% CI 1.36-3.11) at 3 months in random model $\left(p<0.0001, I^{2}=77 \%\right)$ and OR of 1.50

Table 1 Characteristics of individual studies included in meta-analysis

\begin{tabular}{|c|c|c|c|c|c|c|c|c|c|c|c|}
\hline \multirow[t]{2}{*}{ Author } & \multirow[t]{2}{*}{ Year } & \multicolumn{2}{|c|}{ Number of participants } & \multicolumn{2}{|l|}{ Age (years) ${ }^{a}$} & \multicolumn{2}{|c|}{ Sexual Satisfaction } & \multicolumn{2}{|c|}{ Resumed Intercourse } & \multicolumn{2}{|c|}{ Sexual Pain } \\
\hline & & $C D$ & VD & $C D$ & VD & 3 months & 6 months & 3 months & 6 months & 3 months & 6 months \\
\hline$X U X Y$ & 2003 & 260 & 142 & - & - & $\mathrm{N}$ & $\mathrm{Y}$ & $\mathrm{N}$ & $\mathrm{N}$ & $\mathrm{N}$ & Y \\
\hline Xing $Y X$ & 2007 & 225 & 256 & $25.30 \pm 2.15$ & $24.6 \pm 2.36$ & Y & Y & Y & Y & Y & Y \\
\hline Zhang GP & 2009 & 98 & 96 & $20-30$ & $20-30$ & Y & Y & Y & Y & Y & Y \\
\hline Mai XL & 2011 & 206 & 224 & $25-29$ & $25-29$ & $\mathrm{~N}$ & $\mathrm{~N}$ & Y & Y & Y & Y \\
\hline Wang SG & 2012 & 100 & 140 & $21-33$ & $21-33$ & Y & Y & Y & Y & Y & Y \\
\hline Liu D & 2013 & 230 & 170 & $20-32$ & $20-32$ & Y & Y & Y & Y & $N$ & Y \\
\hline Yu QY & 2014 & 114 & 75 & $26.41 \pm 2.25$ & $26.39 \pm 2.21$ & $N$ & $N$ & Y & Y & Y & $N$ \\
\hline Chen J & 2014 & 100 & 100 & $25.90 \pm 1.60$ & $26.30 \pm 2.10$ & Y & Y & Y & Y & Y & Y \\
\hline ZULIFEIYA A & 2015 & 115 & 80 & $25.50 \pm 3.30$ & $26.50 \pm 3.50$ & $\mathrm{~N}$ & $N$ & Y & Y & $\mathrm{N}$ & $\mathrm{N}$ \\
\hline Du ZL & 2015 & 64 & 56 & - & - & $\mathrm{N}$ & $\mathrm{N}$ & Y & $\mathrm{N}$ & $Y$ & $\mathrm{~N}$ \\
\hline
\end{tabular}


Table 2 Meta-analysis of the association between mode of delivery and postpartum sexual function

\begin{tabular}{|c|c|c|c|c|c|c|c|c|c|}
\hline \multirow[t]{2}{*}{ Variables } & & \multirow{2}{*}{$\begin{array}{l}\text { Eligible } \\
\text { Studies }\end{array}$} & \multicolumn{2}{|c|}{ Number } & \multirow[t]{2}{*}{ OR $(95 \% \mathrm{Cl})$} & \multirow[t]{2}{*}{$P$} & \multicolumn{2}{|c|}{ Heterogeneity Test } & \multirow[t]{2}{*}{ Effect Model } \\
\hline & & & $\overline{C D}$ & VD & & & $P$ & $P^{2}(\%)$ & \\
\hline \multicolumn{10}{|c|}{ Sexual Satisfaction } \\
\hline & 3 month & 5 & 740 & 742 & $1.53(0.93,2.49)$ & 0.09 & 0.0007 & 79 & Random \\
\hline & 6 month & 6 & 1011 & 901 & $1.15(0.95,1.39)$ & 0.16 & 0.99 & 0 & Fixed \\
\hline \multicolumn{10}{|c|}{ Resumed Intercourse } \\
\hline & 3 month & 9 & 1252 & 1197 & $2.05(1.36,3.11)$ & 0.0007 & $<0.0001$ & 77 & Random \\
\hline & 6 month & 8 & 1188 & 1141 & $1.50(1.04,2.16)$ & 0.03 & 0.56 & 0 & Fixed \\
\hline \multicolumn{10}{|c|}{ Sexual Pain } \\
\hline & 3 month & 7 & 1010 & 1022 & $0.29(0.24,0.36)$ & $<0.00001$ & 0.63 & 0 & Fixed \\
\hline & 6 month & 7 & 1223 & 1126 & $0.73(0.58,0.93)$ & 0.01 & 0.76 & 0 & Fixed \\
\hline
\end{tabular}

$C D$ cesarean delivery, VD spontaneous vaginal delivery, OR odds ratios, $95 \% \mathrm{Cl} 95 \%$ confidence interval

(95\% CI 1.04-2.16) at 6 months in fixed model $(p<0.56$, $I^{2}=0 \%$ ), respectively (Fig. 4 ).

In the sexual pain domain, there were 2032 (seven articles) and 2349 participants (seven articles) in postpartum at 3 months and 6 months, respectively. Compared with vaginal delivery group, less sexual pain was all observed in cesarean delivery group at 3 months $(\mathrm{OR}=0.29,95 \% \mathrm{CI}$ $0.24,0.36)$ and at 6 months $(\mathrm{OR}=0.73,95 \% \mathrm{CI} 0.58,0.93)$, respectively (Fig. 5). Because of the insignificant heterogeneity between studies, they were all determined using the fixed effect method $\left(p<0.63, I^{2}=0 \%, p<0.76, I^{2}=0 \%\right.$; respectively).

When any single study was deleted, sensitivity analysis was indicated a good stability of the meta-analysis in each domain (Additional file 2: Table S2; Additional file 3: Figures S3-S6).

\section{Discussion}

To the best of our knowledge, this is the first metaanalysis that examines the results association between postpartum sexual function and the mode of delivery, cesarean and spontaneous vaginal delivery, in Chinese primiparous women. The results indicated that two of the three domains (resumed intercourse and sexual pain) in both short-term (3 months later) and long-term (6 months later) were all better in cesarean delivery group. However, with the passage of time, the gap was closing. The sexual satisfaction was all not found

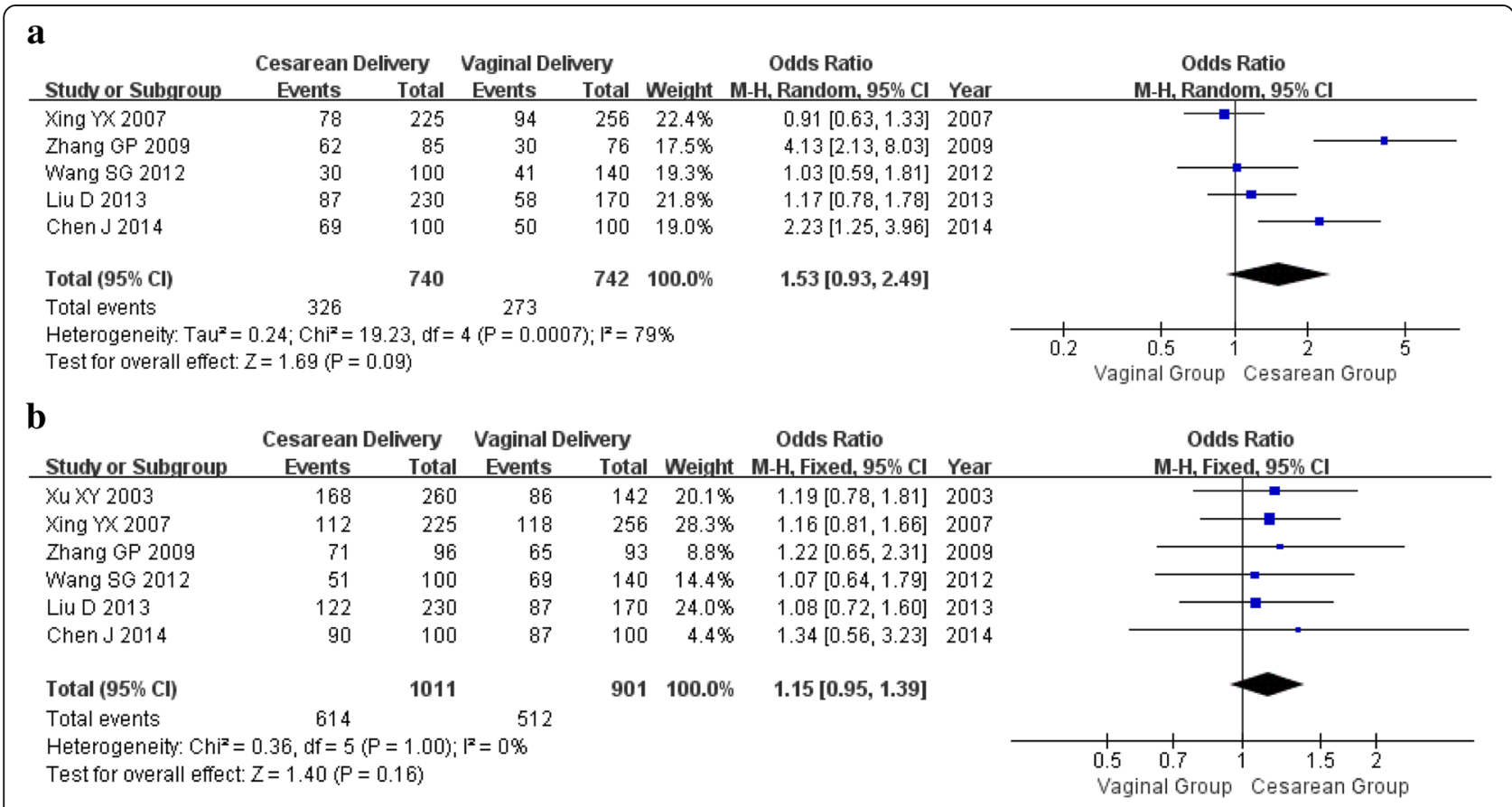

Fig. 3 Forest plot of sexual satisfaction and mode of delivery. a within 3 months after delivery; (b) within 6 months after delivery 


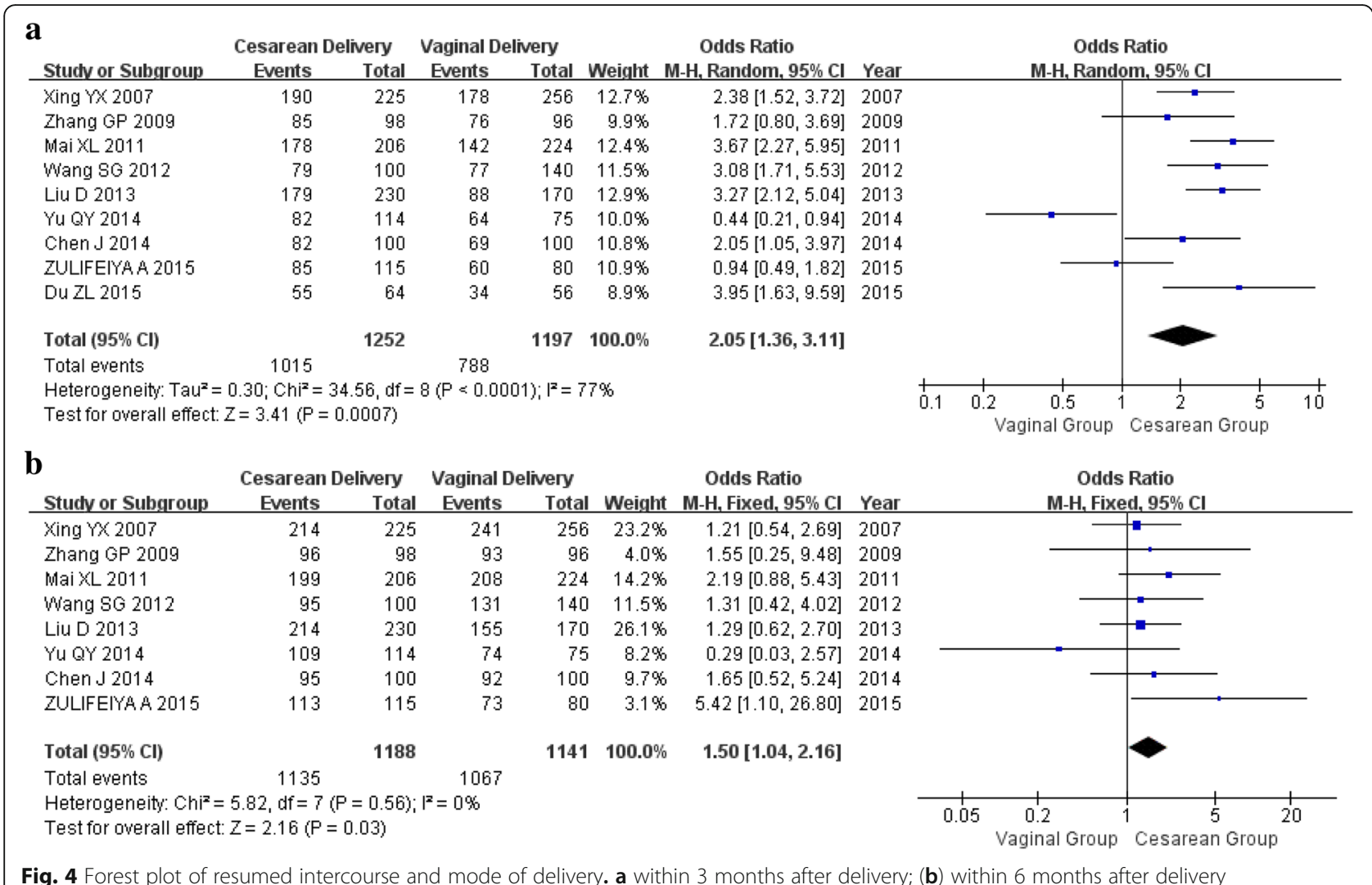

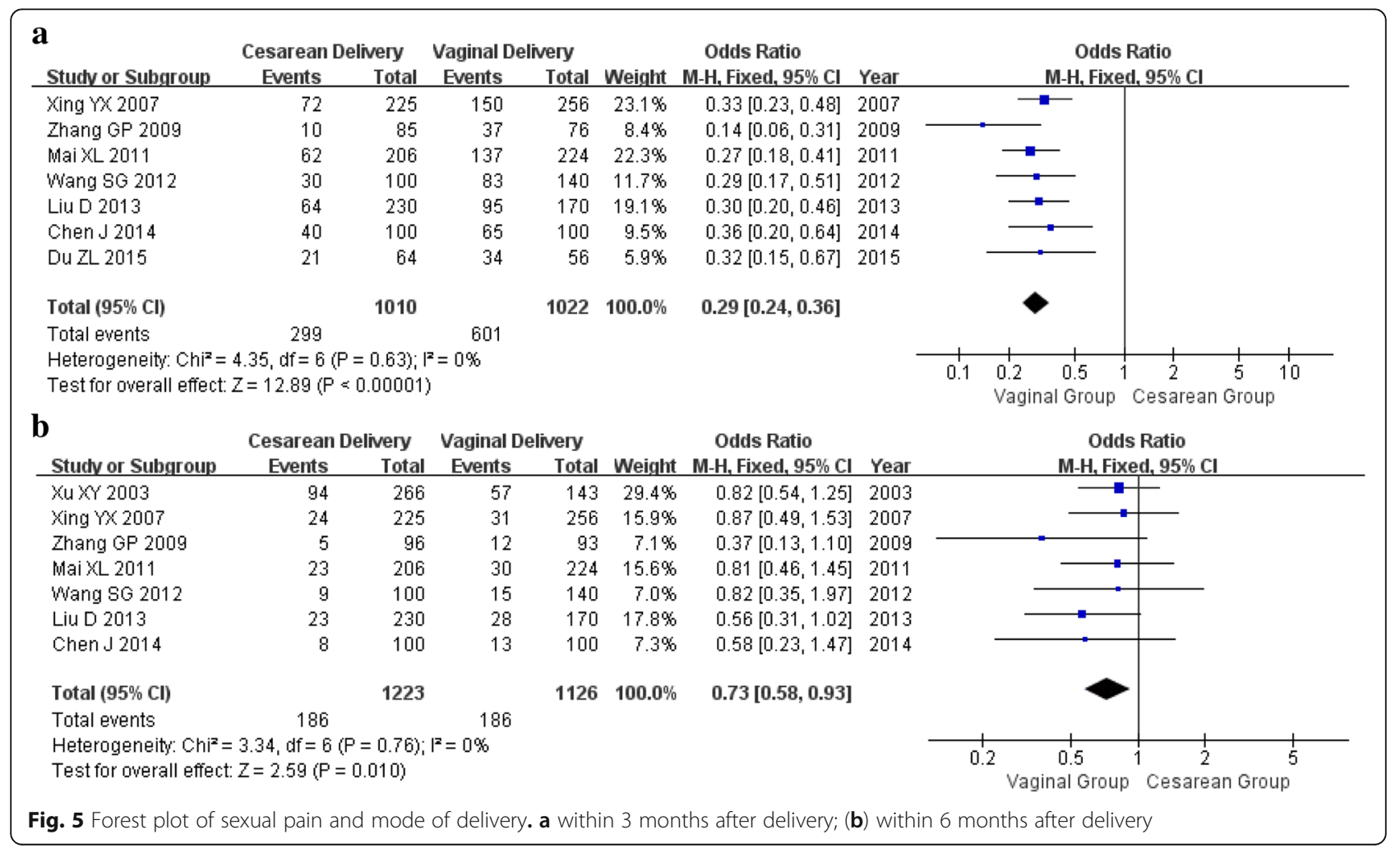


different at short- and long-term postpartum in the two delivery models.

Sexual health is an important aspect of quality of life. Studies [30-32] have reported that diseases could affect the sexual function. Many studies have focused on the mode of delivery and postpartum sexual health [33-35], however, these results are still inconsistent. In a crosssectional postal survey study [34], Dean and colleagues showed that sexual satisfaction was significantly less in women with vaginal delivery than the women who had undergone a cesarean section. However, in another similar cross-sectional study of primiparous women [35], Hosseini et al. reported that women in the normal vaginal delivery group and planned cesarean section group had no significant difference in the sexual function, including sexual satisfaction and pain, and he appealed that undergoing planned cesarean section in order to preserve sexual function was not recommended.

In this meta-analysis study, the results indicated that sexual satisfaction was all not found different in the 3 and 6 months postpartum. In the study of 1159 Canadian postpartum women [36], Hannah and colleagues reported that sexual satisfaction from 3 months to 2 years postpartum was similar among women who had undergone a planned cesarean section and planned vaginal birth. Meanwhile, similar results were also showed in other studies [34, 37, 38].

Although other two domains (resumed intercourse and sexual pain) in both short-term (3 months later) and longterm (6 months later) were better in cesarean delivery group, with the passage of time, the gap was closing. In the study by a postal survey conducted on 484 British primiparous women at 6 months after delivery [39], resumption of sexual intercourse did not differ significantly by type of birth. Meanwhile, women who had undergone cesarean sections were significantly less likely to experience sexual dysfunction at 3 months postpartum, but there was no significant difference at 6 months.

The results of the sensitivity analysis were not materially altered and did not draw different conclusions, indicating that the initial results were strong. However, some limitations also need to be discussed. First, this meta-analysis was based on data from studies whose results had been published, and some relevant studies could not be included in our analysis. Due to the small number of the included studies, publication bias cannot be assessed. Meanwhile, some items of the STROBE Statement were not reported in the included studies, which could increase the high risk of bias. Second, the meta-analysis was limited to different adjustments for potential confounding variables (age, area, primiparous/ multiparous, et al.) in each study. Because of lacking sufficient data, we cannot exclude the possibility that these factors, which may affect the final conclusion of the present study. Third, the results were based on selfcreated questionnaire among studies, which may result in some misclassification bias. In addition, various outcome measures (resumption of sexual activity, satisfaction or orgasm, sexual sensation, sexual inactivity) assessed the postpartum sexual problems for women. Because most Chinese doctors just focus on the three domains, we cannot assess all of the domains of their postpartum sexual problems.

\section{Conclusions}

This meta-analysis indicated that the mode of delivery, cesarean delivery, and vaginal delivery did not affect postpartum sexual satisfaction (short- and long-term) and appeared to have minimal effect on the long-term resumed intercourse and sexual pain in Chinese primiparous women. Postpartum sexual dysfunction may be affected to prepartum sexual function, the partner's experience, and other social and cultural factors. Those requesting caesarean delivery without conventional medical indications or obstetric indications for foetus or mother, should be advised of these potential results.

It is important to inform pregnant women that the mode of delivery is not a major factor in postpartum sexual dysfunction. Meanwhile, in clinical practice, more attention should be given to the relationship between the mode of delivery and postpartum sexual function, especially primiparous women. Obstetricians, nursing staffs, and all of the health care providers who are engaged in counseling couples during the antepartum period should be told in order to train couples regarding potential postpartum sexual dysfunction to help these couples chose the mode of delivery.

\section{Additional files}

Additional file 1: Table S1. PRISMA Checklist. (DOC 64 kb)

Additional file 2: Table S2. The results of the included studies through sensitivity analysis. (DOC $98 \mathrm{~kb}$ )

Additional file 3: The results of the included studies through sensitivity analysis. Figure S1. Sensitivity analysis of 5 studies with the random effects model for sexual satisfaction within 3 months after delivery. Figure S2. Sensitivity analysis of 6 studies with the fixed effects model for sexual satisfaction within 6 months after delivery. Figure S3. Sensitivity analysis of 9 studies with the random effects model for resumed intercourse within 3 months after delivery. Figure $\mathbf{S 4}$. Sensitivity analysis of 8 studies with the fixed effects model for resumed intercourse within 6 months after delivery. Figure S5. Sensitivity analysis of 7 studies with the fixed effects model for sexual pain within 3 months after delivery. Figure $\mathbf{5 6}$. Sensitivity analysis of 7 studies with the fixed effects model for sexual pain within 6 months after delivery. (DOCX $957 \mathrm{~kb}$ )

\section{Abbreviations}

CBM: The Chinese biological medical literature database; CD: Cesarean delivery; Cl: Confidence interval; CNKI: The Chinese national knowledge infrastructure database; NOS: Newcastle-Ottawa Scale; OR: Odds ratio; PRISMA: The preferred reporting items for systematic reviews and meta-analysis; STROBE: The 
strengthening the reporting of observational studies in epidemiology; VD: Spontaneous vaginal delivery

\section{Acknowledgments}

We appreciate the efforts of all the researchers whose articles were included in this study.

\section{Funding}

The author(s) received no specific funding for this work.

\section{Availability of data and materials}

All data analyzed during this study are presented within the manuscript (Tables 1 and 2).

\section{Authors' contributions}

ZL and XG participated in the design and coordination of the study. DF conceived the study, and drafting the manuscript. SL searched for the studies, collected and analyzed the data. WW participated in the design of this study and edited the manuscript. GT and LL did the data management and analyzed the data. SW conceived the study. All authors read and approved the final manuscript.

\section{Ethics approval and consent to participate}

Not applicable.

\section{Consent for publication}

Not applicable.

\section{Competing interests}

The authors declare that they have no competing interests.

\section{Publisher's Note}

Springer Nature remains neutral with regard to jurisdictional claims in published maps and institutional affiliations.

\section{Author details}

${ }^{1}$ Foshan Institute of Fetal Medicine, Southern Medical University Affiliated Maternal \& Child Health Hospital of Foshan, Foshan, Guangdong 528000 China. ${ }^{2}$ Department of Obstetrics, Southern Medical University Affiliated Maternal \& Child Health Hospital of Foshan, Foshan, Guangdong 528000, China. ${ }^{3}$ Department of Epidemiology and Biostatistics, School of Public Health, Anhui Medical University, Hefei, Anhui 230032, China. ${ }^{4}$ Chaohu Hospital Affiliated Anhui Medical University, Chaohu, Anhui 238000, China. ${ }^{5}$ The First Affiliated Hospital, College of Medicine, Zhejiang University, Hang Zhou, Zhejiang 310003, China. ${ }^{6}$ School of Integrated Traditional and Western Medicine, Anhui University of Chinese Medicine, Hefei, Anhui 230038, China.

Received: 24 November 2015 Accepted: 17 November 2017

Published online: 06 December 2017

\section{References}

1. Betran AP, Merialdi M, Lauer JA, Bing-Shun W, Thomas J, Van Look P, et al. Rates of caesarean section: analysis of global, regional and national estimates. Paediatr Perinat Epidemiol. 2007:21:98-113.

2. Leone T, Padmadas SS, Matthews Z. Community factors affecting rising caesarean section rates in developing countries: an analysis of six countries. Soc Sci Med. 2008;67:1236-46.

3. Wang BS, Zhou LF, Coulter D, Liang H, Zhong Y, Guo YN, et al. Effects of caesarean section on maternal health in low risk nulliparous women: a prospective matched cohort study in shanghai, China. BMC Pregnancy Childbirth. 2010;10:78.

4. Organization WH. Appropriate technology for birth. Lancet. 1985:2:436-7.

5. Zelop C, Heffner $L$ J. The downside of cesarean delivery: short- and long-term complications. Clin Obstet Gynecol. 2004;47:386-93.

6. Health Institutes of Health. National Institutes of Health state-of-the-science conference statement: cesarean delivery on maternal request march 27-29, 2006. Obstet Gynecol. 2006:107:1386-97.

7. Fan D, Wu S, Wang W, Xin L, Tian G, Liu L, et al. Prevalence of placenta previa among deliveries in mainland China: a PRISMA-compliant systematic review and meta-analysis. Medicine (Baltimore). 2016;95:e5107.
8. Leader-Cramer A, Kenton K, Dave B, Gossett DR, Mueller M, Lewicky-Gaupp C. Factors associated with timing of return to intercourse after obstetric anal sphincter injuries. J Sex Med. 2016;13:1523-9.

9. Rogers RG, Borders N, Leeman LM, Albers LL. Does spontaneous genital tract trauma impact postpartum sexual function? J Midwifery Womens Health. 2009:54:98-103.

10. Zhang H, Fan S, Yip PS. Sexual dysfunction among reproductive-aged Chinese married women in Hong Kong: prevalence, risk factors, and associated consequences. J Sex Med. 2015;12:738-45.

11. Abdool Z, Thakar R, Sultan AH. Postpartum female sexual function. Eur J Obstet Gynecol Reprod Biol. 2009;145:133-7.

12. Declercq E, Cunningham DK, Johnson C, Sakala C. Mothers' reports of postpartum pain associated with vaginal and cesarean deliveries: results of a national survey. Birth. 2008;35:16-24.

13. Andreucci CB, Bussadori JC, Pacagnella RC, Chou D, Filippi V, Say L, et al. Sexual life and dysfunction after maternal morbidity: a systematic review. BMC Pregnancy Childbirth. 2015;15:307.

14. Rowlands IJ, Redshaw M. Mode of birth and women's psychological and physical wellbeing in the postnatal period. BMC Pregnancy Childbirth. 2012;12:138.

15. Feng $X \mathrm{~L}, \mathrm{Xu} \mathrm{L}, \mathrm{Guo} Y$, Ronsmans $\mathrm{C}$. Factors influencing rising caesarean section rates in China between 1988 and 2008. Bull World Health Organ. 2012:90:30-9. 39A

16. ZULIFEIYA A, MIREAYI G. Impact of different methods of delivery on the postpartum sexual function of primipara. The Chinese Journal of Human Sexuality. 2015;24:74-6.

17. Du ZL. Impact Of different modes of delivery on postpartum sexual function of primiparae. Guide of China. Medicine. 2015:13:172-3.

18. QY Y, Zhang SZ. Impact of different modes of delivery on postpartum sexual function of primiparae. The Chinese Journal of Human Sexuality. 2014;23:32-6.

19. Chen J, Qi J, He Y. Impact of natural birth and cesarean section of female postpartum sexual function and living quality. The Chinese Journal of Human Sexuality. 2014:23:62-5.

20. Liu D. Impact of natural birth and cesarean section of female postpartum sexual function and living quality. Qingdao medical. Journal. 2013:45:263-4.

21. Wang SG, Chen XY, Zhou LP, Ruan Z, FL H, Chen F, et al. A comparison on the effect of cesarean and vaginal delivery on women's postpartum sexual function. The. Chinese Journal of Human Sexuality. 2012;21:19-21.

22. Mai $X \mathrm{~L}$, Long LS. Impact of different methods of delivery on the postpartum sexual function. National Medical Frontiers of China. 2011;6:51-2.

23. Zhang GP, Xie $C L$, Shen X. Impact of different methods of delivery on the postpartum sexual function. TODAY NURSE. 2009:73-4.

24. Xing YX, Guo JQ, Yang LZ, Hou YL, Li FJ. Women's sexual health after birth between abdominal delivery and vagina delivery. China Journal of Modern Medicine. 2007;17:215-9

25. XY X, Yao ZW, Wang HY, Zhou Q, Zhang LW. Women's postpartum sexuality and delivery types. Chin. J Obstet Gynecol. 2003;38:219-22.

26. Moher D, Liberati A, Tetzlaff J, Altman DG, Group P. Preferred reporting items for systematic reviews and meta-analyses: the PRISMA statement. Int J Surg. 2010;8:336-41.

27. von Elm E, Altman DG, Egger M, Pocock SJ, Gotzsche PC, Vandenbroucke $J P$, et al. The strengthening the reporting of observational studies in epidemiology (STROBE) statement: guidelines for reporting observational studies. Int J Surg. 2014;12:1495-9.

28. Umer A, Kelley GA, Cottrell LE, Giacobbi P Jr, Innes KE, Lilly CL. Childhood obesity and adult cardiovascular disease risk factors: a systematic review with meta-analysis. BMC Public Health. 2017;17:683.

29. Fan D, Liu S, Yang T, Wu S, Wang S, Li G, et al. Association between KIR polymorphisms and ankylosing spondylitis in populations: a meta-analysis. Mod Rheumatol. 2014

30. Yin R, Xu B, Li L, Fu T, Zhang L, Zhang Q, et al. The impact of systemic lupus erythematosus on women's sexual functioning: a systematic review and meta-analysis. Medicine (Baltimore). 2017:96:e7162.

31. Fan D, Liu L, Ding N, Liu S, Hu Y, Cai G, et al. Male sexual dysfunction and ankylosing spondylitis: a systematic review and metaanalysis. J Rheumatol. 2015;42:252-7

32. Zhang Q, Zhou C, Chen H, Zhao Q, Li L, Cui Y, et al. Rheumatoid arthritis is associated with negatively variable impacts on domains of female sexual function: evidence from a systematic review and meta-analysis. Psychol Health Med. 2017:1-12. 
33. De Souza A, Dwyer PL, Charity M, Thomas E, Ferreira C, Schierlitz L. The effects of mode delivery on postpartum sexual function: a prospective study. BJOG. 2015;122:1410-8.

34. Dean N, Wilson D, Herbison P, Glazener C, Aung T, Macarthur C. Sexual function, delivery mode history, pelvic floor muscle exercises and incontinence: a cross-sectional study six years post-partum. Aust N Z J Obstet Gynaecol. 2008;48:302-11.

35. Hosseini L, Iran-Pour E, Safarinejad MR. Sexual function of primiparous women after elective cesarean section and normal vaginal delivery. Urol J. 2012;9:498-504.

36. Hannah ME, Whyte H, Hannah WJ, Hewson S, Amankwah K, Cheng M, et al. Maternal outcomes at 2 years after planned cesarean section versus planned vaginal birth for breech presentation at term: the international randomized term breech trial. Am J Obstet Gynecol. 2004;191:917-27.

37. van Brummen $\mathrm{HJ}$, Bruinse HW, van de Pol G, Heintz AP, van der Vaart $\mathrm{CH}$. Which factors determine the sexual function 1 year after childbirth? BJOG. 2006;113:914-8.

38. Gungor S, Baser I, Ceyhan T, Karasahin E, Kilic S. Does mode of delivery affect sexual functioning of the man partner? J Sex Med. 2008:5:155-63.

39. Barrett G, Peacock J, Victor CR, Manyonda I. Cesarean section and postnatal sexual health. Birth. 2005;32:306-11.

\section{Submit your next manuscript to BioMed Central} and we will help you at every step:

- We accept pre-submission inquiries

- Our selector tool helps you to find the most relevant journal

- We provide round the clock customer support

- Convenient online submission

- Thorough peer review

- Inclusion in PubMed and all major indexing services

- Maximum visibility for your research

Submit your manuscript at www.biomedcentral.com/submit 